\title{
Analysis on the Irrationality and Abnormality in Life
}

\author{
Mofei Chen
}

\author{
Northeast Yucai Foreign Language School, Shenyang, Liaoning,110000, China \\ 1977966996@qq.com
}

\begin{abstract}
This passage mainly focuses on two aspects. One is the irrational behavior people make while dealing with issues that involve gain and loss. The other is the analysis of one major economic incentive for people to cheat, experiments for testing the theory that money can be a strong incentive for cheating, and measures to prevent it. The author finds out that people have a universal preference for things that are free to obtain and an active dislike of loss. This natural preference may result in irrational decision-making while trading. Moreover, the author proves through experiment that money can be a highly influential incentive for people to commit dishonest behavior.
\end{abstract}

Keywords: Irrational behavior, trust, cheating, classical economics

\section{INTRODUCTION}

The founder of classical economics, Adam Smith, put up an idea of rational people assuming that people will prioritize their own benefits rather than the overall profits of the entire society. Two words used to refer to these people in classical economics were self-interested and rational [1]. However, it is universally acknowledged that economic operation and market behavior are unpredictable, unlike the orderly world depicted in the theory of classical economics. One of the main factors contributing to this unpredictability might be that humans are born not to be rational and completely self-interested. Social phenomena like interpersonal relationship, responsibility, or self-esteem constantly and imperceptibly influence the decisions of people. As a result, people often behave inconsistently with what the classical economists predict. The irrationality of human beings inspired the author to find out more about these irrational behaviors in our real-world, the psychological understanding of them and the impact these behaviors can have. The paper provides readers with a better understanding of the motivation behind these irrational behaviors, which may allow people to take advantage of the benefits while avoiding the negative effects.

\subsection{The Effect that Free Things Have on People's Decisions}

Most deals and trades have their pros and cons, but free covers the negative side. Things that are free give rise to an emotional impulse to falsely overvalue the free goods. Due to the human instinctive fear of loss, free provides people with a sense of assurance and security. Since there's no obvious loss in choosing things that are free, people may run the risk of losing more than they gain if they choose something that is not free. In an experiment done by Dan Ariely, he once sold chocolate to passersby. Two kinds of chocolate were sold; Lindt Lindor Truffle Milk Chocolate and Hershey's Kiss. The Hershey's kiss chocolate is sold for one cent and Lindt Lindor Truffle Milk chocolate, as the representative of high-quality chocolate, was sold for 15 cents each. The results of sales at the given price seems quite logical with $73 \%$ of participants choosing Lindt Lindor Truffle Milk chocolate that is of higher quality and value comparing with the Hershey's Kiss. What would happen if the price of two kinds of chocolate were decreased simultaneously for one cent, that is 14 cents for Lindt Lindor Truffle Milk Chocolate and free of charge for the Hershey's chocolate? According to the theory of neoclassical economics, since both selections were lowered for the same price, people's preference shouldn't be changed. While the results were astonishing with a drop of the amount of people purchasing Lindt Lindor Truffle Milk Chocolate from $73 \%$ to $31 \%$. Rational decision-making theory is always utilized by the economists when evaluating human behaviors [2]. 


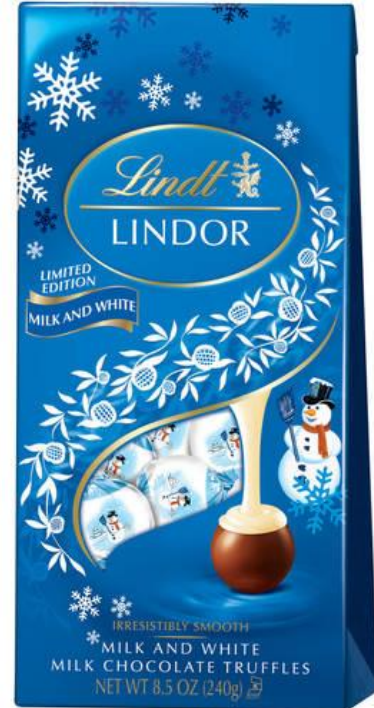

Figure 1. Lindor Truffle Milk chocolate, the representative of the premium chocolate

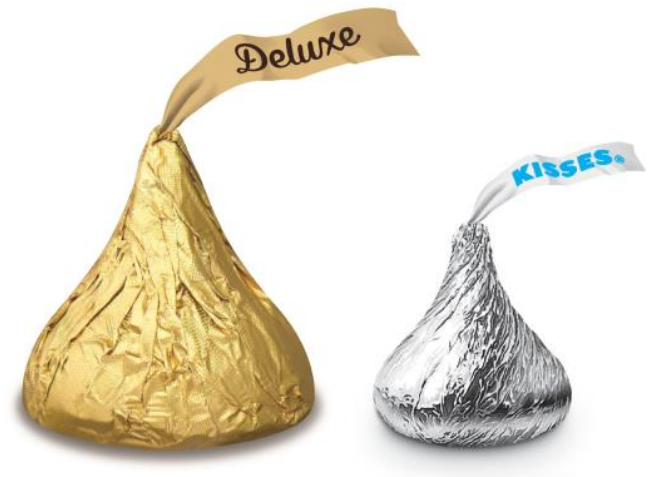

Figure 2. Hershey's Kiss, work of mass production

The theory assumes that when choosing behaviors, people will estimate the benefits and costs of different behaviors, and choose behaviors in a rational way, that is, to obtain the maximum benefits at the lowest cost. In short, if people meet their expectations at a small cost, you will act and seek to maximize your benefits. For example, people would be willing to scan the QR code to get a gift for free. Traditional economists believe that people are rational and pursue the maximization of profits, but this is not always consistent with people's psychology and behavior in actual investment.

\subsubsection{The psychological bias between gain and loss affects people's decisions}

Let me give you two examples from behavioral economics. In the first situation, two options are provided.

A: You are sure to have thirty thousand dollars in profits

B: There's an $80 \%$ chance that you'll get $\$ 40,000$, and a $20 \%$ chance that you'll get nothing.
What would you choose? The results show that over $60 \%$ of the participants choose A and choose to receive $\$ 30,000$. However, when we think and evaluate rationally like classical economists do, we may find out that option B $(\$ 40,000 * 80 \%=\$ 32,000>\$ 30,000)$ ought to be the most rational and most profitable plan.

We can assume from the irrational result that people are more likely to choose the certain profits rather than gambling and risking for greater earnings. It is often observed while people are making investment. When they are in the state of profit, they are often afraid of losses and give up potential opportunities for greater gains.

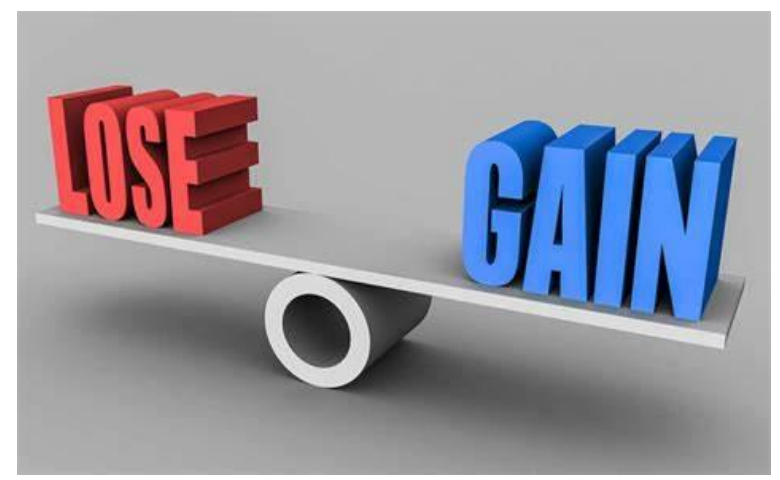

Figure. 3 The balance between Gain and Lose

\subsubsection{People are more inclined to gamble when the choice is between a certain loss and a bet}

In another situation that have two options:

A: You're sure to lose $\$ 30,000$

B: there's an $80 \%$ chance you'll lose $\$ 40,000$, and a $20 \%$ chance you won't have to lose at all

What would you choose? Most people are willing to take a gamble and choose B. However, the conclusion of rational thinking on this issue should be $(-40,000$ $* 80 \%=-32,000)$, greater than $-30,000$, and choice $\mathrm{A}$ is the optimal plan.

In reality, when encountered with situation that involves loss, people are more likely to take a bigger risk, only to suffer from greater loss. These two examples are common situations in the real world, which are caused by the fact that most people have different sensitivity to gain and loss. Furthermore, the happiness gained by the same amount is not as great as the sadness of loss. For example, in a fair bet, would you be willing to bet if you bought the big bet to win 100 and bought the small bet to lose 100? Most people are reluctant to bet because the underlying psychological logic is that the happiness of gaining 100 is less than the sadness of losing 100. 


\subsubsection{Discussion}

In the daily investment, there are people who regularly check their accounts to see what happens to their assets or stocks they bought, which I personally think is a very harmful habit. It indicates the lack of vision for a bigger picture. Most of the time, the price fluctuates back and forth, bringing pleasure or sadness. When the price moves around a range for a period of time but the asset has not changed at all, the person's mindset may already be negatively influenced. The reasonable way should be to have a clear upper and lower expected value, do not pay attention to it when it is far from the expected value, and deal with it decisively when it reaches the expected value.

In investment, we need to understand the behavior behind economics, namely that human nature is partly perceptual, partly rational, and each may be weighted differently. In many cases, people will inadvertently make decisions based on emotion, and fall into the misunderstandings as mentioned in the examples above. Even though we calculate the optimal scheme by mathematical method, we are still unwilling to do it because it is not in accordance with our own sensibility. However, a person with a higher rational score has an advantage in the financial market. $\mathrm{He}$ or she can consider the solution from all aspects, which will reduce unnecessary losses and increase the space for profits. That may not seem like much, but financial investments are long-term and add up to a lot of money.

So, in the long run, those who invest rationally are more profitable than those who invest sensibly.

\subsection{Why People Lie}

Robberies nationwide totally involved $\$ 525$ million in 2004, with an average of $\$ 1,300$ per case. While each year the loss of money caused by employee theft and fraud was 600 million, it far outpaces the rate of violent crime during the same period [3]. The dishonest behavior has been causing great damage to the tranquility of society. But why do people lie? According to the Husson University, three motivations can result in people's major lying behavior: to promote yourself, to protect yourself, and to impact others [4]. In the real world, money incentive, as the author assumes, is one of the most common and influential driving forces that lures people to cheat or lie to maximize their profits. To test whether money can be an incentive to people, the author designed an experiment to find out whether money can be a reason for people to cheat. The author divided the participants into two groups and each group was told to take a test. The experiment was done four times. The first time was in a completely fair environment; strictly supervised by teachers without any money or bonus as incentive. Additionally, all the participants were told that the scores would not have any effect to their GPA and would not be reported to their parents. The results were 5 people winning the bonus and the average score of the group is 66.4. In the second time, the test was still done in a completely fair environment with strict supervision from teachers. If the participants score over 85, they may have the bonus; one yuan for each point higher than 85 with the maximum bonus being 100 . The only variable in the second time was the use of a bonus as a lure. The result of the second round is 16 people scored over 85 and won the bonus. The average score for the entire group is 78.3. When compared with the results of group one, it is obvious that the performance of the second time is way better than that of the first time. For the third round, no bonus and no supervision, the students are given perfect chances to cheat but the results showed that the number of people scoring over 85 and the average score is almost the same with those of the first time. The last round, no supervision but a bonus was provided. It is no surprise that the performance of the last trial would be result in the highest scores. Indeed, people may have slight differences in their academic ability, but the overall tendency is convincing and persuasive. Are the participants in the second and last test better at doing tests? Not likely. The bonus provided served as an incentive and motivation that lured students to cheat regardless of the strict inspection and risks of being caught. That is why we can often observe government officers, administrators involved in corruption despite the risks of losing their job or even being sent to prison. From the experiment, it is obvious that money provides people with sufficient reason to abandon their professional standards or social obligations. From each year's loss of money caused by financial crime, it is therefore critical to find a solution that can effectively reduce the negative impact. Since people value money so much, it can be effective if monetary punishment is set to eliminate the cheating phenomena. Using the theory of neoclassical economics, people will try their best to maximize their profits.[5] In this case, if the penalties for being caught cheating exceeded the value of the bonus, people would be discouraged from taking risks. Besides that, signing guarantees in advance can be a common measure utilized. Whether the supervisors are present or not, the guarantees that people sign can serve as a reminder of the ethical considerations which prevent people from cheating.

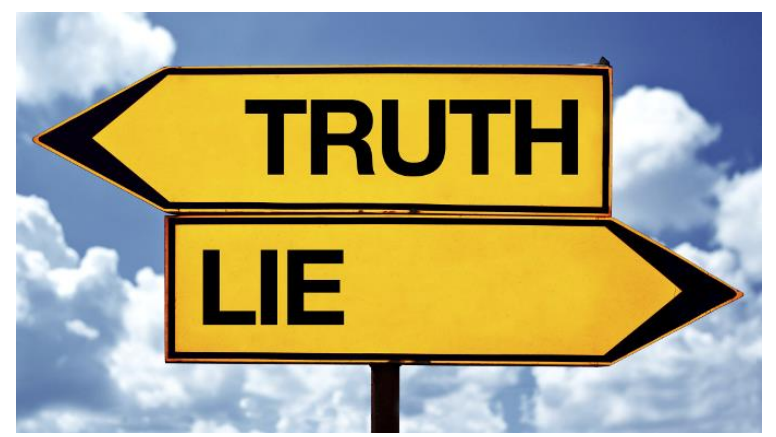

Figure 4. Why people choose to lie? 


\section{CONCLUSION}

In the real world, people can be irrational when dealing with situations that involve gain and loss. Humans are born to have preference for things that are free; even if the alternative can be more economically profitable, people have stronger preference for the free stuff. However, in the case of losing, people prefer to gamble instead of losing a definite amount of money which is a better choice. The human instinct that author believes to have negative influence on the decisions that people make especially on investment.

Money incentive was tested by the author and found to be a highly influential factor that tempts people to cheat in competition. The loss of money caused by financial crimes greatly exceeds that caused by violent crimes. Later the author proposes resolutions that using severe penalties or appealing to the people's moralities can be effective in reducing people's inclinations for cheating.

\section{ACKNOWLEDGMENT}

I want to show my gratitude to the author of the book Irrational Behavior by Dan Ariely, who provided me with a bright and novel way of evaluating the economic behavior in daily life. Also, I would like to show my deepest gratitude to my teachers who provided me with a suitable condition to complete my experiments and classmates who voluntarily participate in my tests. Without them, I could not have obtained the results and finished my thesis.

\section{REFERENCES}

[1] Will Kenton(Aug 4, 2019) Neoclassical Economics https://www.investopedia.com/terms/n/neoclassical .asp

[2] Dan Ariely "Predictably Irrational:The Forces That Shape Our Decisions" Chapter 2, "The price of free' HapperCollins

[3] US Bureau of Economic Analysis (BEA) Survey of Current Business, July 2004 - Volume 84 -

Number 7, 2004

https://apps.bea.gov/scb/toc/0704cont.htm

[4] Bella DePaulo Ph.D. (Jun 10, 2017) Why Do People Lie to You?-----Eight things about you that tempt other people to lie https://www.psychologytoday.com/us/blog/living-s ingle/201706/why-do-people-lie-you

[5] Prateek Agarwal on (June 30, 2019), Profit Maximization Rule https://www.intelligenteconomist.com/profit-maxi mization-rule/ 